\title{
Projected Drought Conditions over Southern Slope of the Central Himalaya Using CMIP6 Models
}

\author{
Shankar Sharma ${ }^{1} \cdot$ Kalpana Hamal $^{2,3} \cdot$ Nitesh Khadka $^{3,4} \cdot$ Munawar Ali $^{5} \cdot$ Madan Subedi $^{6} \cdot$ Gulfam Hussain $^{3,5}$. \\ Muhammad Azhar Ehsan ${ }^{7}$. Sajjad Saeed ${ }^{8,9} \cdot$ Binod Dawadi $^{1,10}$
}

Received: 12 June 2021 / Revised: 27 August 2021 / Accepted: 28 August 2021 / Published online: 9 September 2021

(c) The Author(s) 2021

\begin{abstract}
Nepal is located on the southern slope of the Central Himalayas and has experienced frequent droughts in the past. In this study, we used an ensemble of 13 biased corrected models from the Coupled Model Intercomparison Project Phase 6 (CMIP6) to assess the future drought conditions over Nepal under three shared socioeconomic pathways (SSP126, SSP245, and SSP585) using the Standardized Precipitation Evapotranspiration Index (SPEI) at annual timescale. The monthly correlation between observed and CMIP6-simulated historical SPEI is $0.23(p<0.01)$, which indicates the CMIP6 model ensemble can simulate the drought characteristics over Nepal. In the future period (2020-2100), the duration and severity of droughts are projected to increase with higher emission scenarios, especially for SSP585. Our results indicate enhanced drought intensity under SSP126, whereas, under SSP245, the drought frequency will be slightly higher. The drought frequency is projected to increase in the early future (2020-2060), decreasing in the late future (2061-2100) under all SSP scenarios. The results further indicate more prolonged and severe droughts in the early future under SSP585 as compared to SSP126 and SSP245. The findings of the present study can help drought mitigation as well as long-term adaptation strategies over Nepal.
\end{abstract}

Keywords Projected drought · Drought characteristics · CMIP6 · SPEI · Central Himalaya · Nepal

\section{Introduction}

Climate change and climate extremes have impacted agriculture production, water resources, environment, and socioeconomic system globally (De Silva and Kawasaki 2018; Hamal et al. 2020b; Van Dijk et al. 2013; Zhou et al. 2015). Meteorological disasters (i.e., drought and floods) are frequent and severe due to the increased global warming and

Binod Dawadi

dawadib@cdhmtu.edu.np

1 Central Department of Hydrology and Meteorology, Tribhuvan University, Kathmandu 44613, Nepal

2 International Center for Climate and Environment Sciences, Institute of Atmospheric Physics, Chinese Academy of Sciences, PO Box 9804, Beijing 100029, China

3 University of Chinese Academy of Sciences, Beijing 100049, China

4 Institute of Mountain Hazards and Environment, Chinese Academy of Sciences, Chengdu 610041, China

5 Institute of Tibetan Plateau Research, Chinese Academy of Sciences, Beijing 100101, China ongoing climate change (Bazaz et al. 2018; Sheffield et al. 2012). These disasters are expected to be more frequent with vigorous intensity and longer duration in the future under different emission scenarios (Huo-Po et al. 2013). Drought is very transient and more devastating; the spatial variation of drought severity will be increased across the monsoon (Kim et al. 2020) and westerly-dominated (Ali et al. 2019; Cook et al. 2000) regions. Therefore, to mitigate the consequences

6 Environment and Social Studies Department, Nepal Electricity Authority, Lazimpat, Kathmandu, Nepal

7 International Research Institute for Climate and Society, Earth Institute at Columbia University, Palisades, NY, USA

8 Earth System Physics Section, The Abdus Salam International Center for Theoretical Physics (ICTP), Trieste, Italy

9 Department of Earth and Environmental Sciences, University of Leuven (KU Leuven), Leuven, Belgium

10 Kathmandu Center for Research and Education, Chinese Academy of Sciences-Tribhuvan University, Kathmandu 44613, Nepal 
of droughts, future drought projections can effectively be used for decision and policy making (Dogan et al. 2012).

Nepal is located in the south Asian monsoon region; however, it has a long history of frequent seasonal and annual drought (Hamal et al. 2020b, 2021; Sharma et al. 2021). The historical drought events were recorded in 1972, 1977, 1982, 1992, 1994, 2002, 2004, 2005, 2006, 2008-2009, 2012, 2013, and 2015 (Chandrasekara et al. 2021; Dahal et al. 2016; Sharma et al. 2021; Wang et al. 2013). Moreover, most previous drought studies have used Standard Precipitation Index (SPI) for drought quantification, which uses only precipitation as a fundamental variable (McKee et al. 1993). There is a paucity of studies concerning drought projections in the southern slope of Central Himalaya, Nepal. Further, Chandrasekara et al. (2021) also suggested a drought projection study over south Asian countries. Concerning the lack of the projected drought conditions over Nepal, a reliable study to quantify future drought conditions is undoubtedly needed. Therefore, we adopted the Standardized Precipitation Evapotranspiration Index (SPEI) (Vicente-Serrano et al. 2010), developed in the context of global warming, for drought projection over Nepal. Considering both precipitation and temperature for drought calculation and its variability at multiple timescales, the SPEI has been widely accepted for drought monitoring and prediction (Almazroui et al. 2020; Hamal et al. 2020b; Vicente-Serrano et al. 2010).

Not only meteorological parameters but also anthropogenic activities and environmental factors can induce and prolong drought conditions (Van Loon et al. 2016; Xu et al. 2019). For instance, a study in northwest China shows that human activities alone account for $70.3 \%$ of desertification, where the climate change impact was only $21.7 \%$ (Zhou et al. 2015). Moreover, anthropogenic forcing, like aerosols and greenhouse gases, may influence precipitation variation over Nepal, leading to dry conditions (Wang et al. 2013). The six-phase of Coupled Model Intercomparison Project (CMIP6) considers shared socioeconomic pathways (SSPs) that are essential sources to unfold the future climate projection with substantially improved emissions, land use scenarios, improved model parameterization, and physical process (Mishra et al. 2020; Riahi et al. 2017). Moreover, it has multiple climate models and improved in stimulating precipitation, temperature, and drought characteristics around the world (Almazroui et al. 2021a, b; Dosio et al. 2021) as well as over the south Asian region (Aadhar and Mishra 2020; Almazroui et al. 2020; Zhai et al. 2020). Therefore, we used multi-ensemble models derived from CMIP6 to estimate Nepal's drought condition based on the three SSP scenarios (SSP126, SSP245, and SSP585).

\section{Materials and Methods}

\subsection{Study Area}

Nepal ( $80^{\circ} 04^{\prime}$ to $88^{\circ} 12^{\prime}$ E, $26^{\circ} 12^{\prime}$ to $30^{\circ} 27^{\prime} \mathrm{N}$ ) occupies an area of $147,516 \mathrm{~km}^{2}$. It has an altitudinal variation that ranges from $\sim 60 \mathrm{~m}$ in the south to $8848 \mathrm{~m}$ a.s.l. in the north. Being located in the tropical northern limit with diversified topography, the country features a very diverse climate from tropical savanna in low-elevation to polar frost in high-the Himalayas (Karki et al. 2015; Nepal et al. 2021; Shrestha et al. 2021). Annual precipitation is predominately governed by the summer monsoon and westerly winter precipitation (Duncan et al. 2013; Ehsan et al. 2017; Kansakar et al. 2004). The Trans-Himalayan region has a dry climate since the main Himalayan range restricts monsoon moisture (Sharma et al. 2020a, c). The southeast part of Nepal is greatly influenced by boreal summer monsoon circulation (Sharma et al. 2020b), like other summer monsoon regions around the world (Ehsan et al. 2021). However, the westerly derived circulation system dominates the northwest part of the country during the winter season (Ehsan 2020; Ehsan et al. 2020, 2021; Hamal et al. 2020a). The four distinct seasons are spring (March-May), summer monsoon (June-September), autumn (October-November), and winter (December-February) (Nayava 1980). The monthly precipitation varies from $\sim 20 \mathrm{~mm}$ to $\sim 480 \mathrm{~mm}$, peak mainly in the monsoon season (June-September) (Fig. 1b). Similarly, mean temperature varies with the highest (lowest) mean temperature of $26^{\circ} \mathrm{C}\left(12{ }^{\circ} \mathrm{C}\right)$ in June (January).

\subsection{Datasets}

\subsubsection{Observation}

The historical monthly precipitation and temperature data from 220 observation stations from 1980 to 2014 were collected from the Department of Hydrology and Meteorology, Government of Nepal (www.dhm.gov.np). The precipitation and temperature records from selected 220 stations were further checked for their historical temporal coverage and completeness. These stations were passed through the homogeneity test to avoid fluctuations and missing values in the datasets using the RHtest software package (Core Team 2013). Due to the application of large-scale data and precipitation being highly variable in space and time (Kidd and Huffman 2011), the missing records were not filled. After the quality control, 112 stations featuring more than $80 \%$ monthly datasets are selected for the current study (Fig. 1a). 

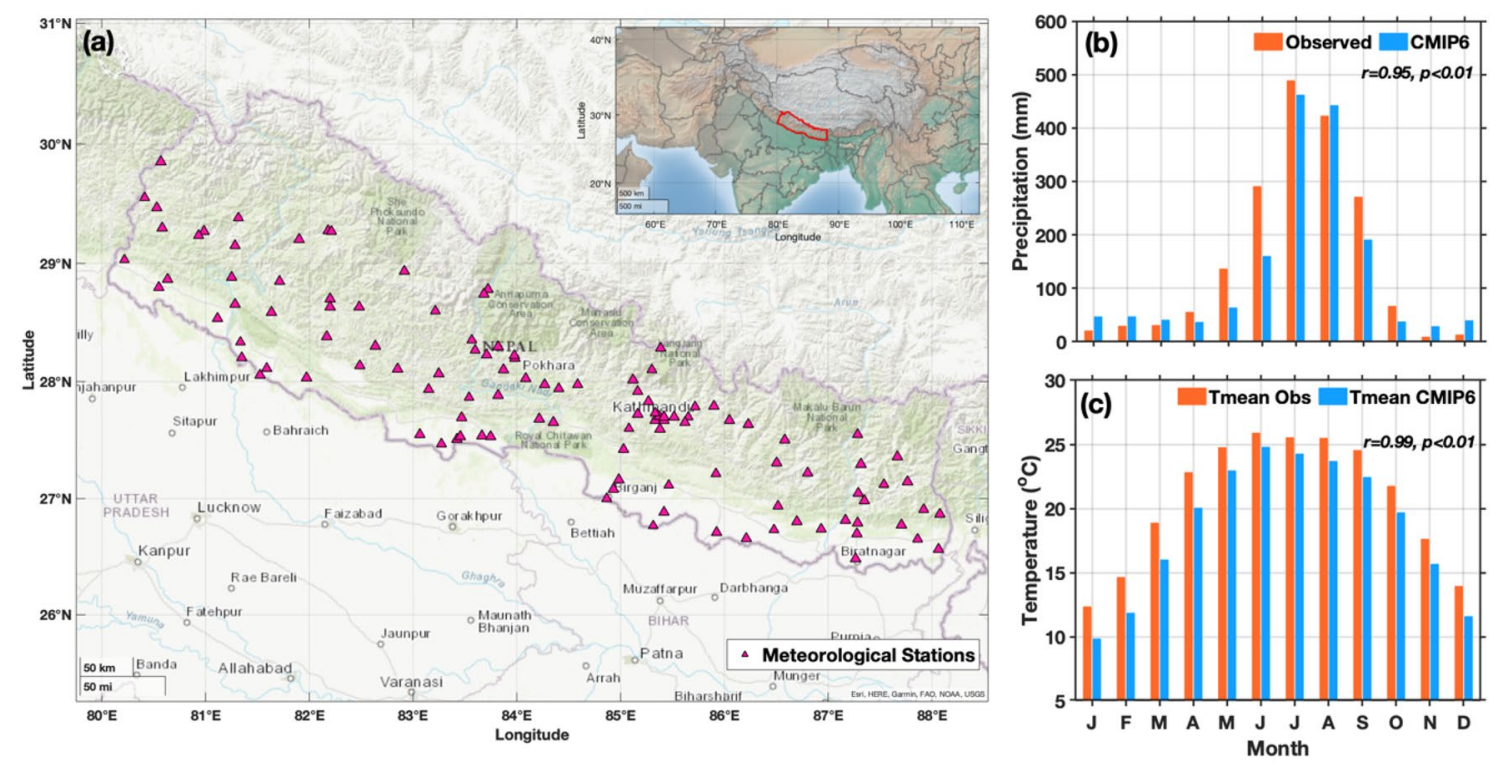

Fig. 1 a Spatial distribution of selected 112 meteorological stations. Observed and CMIP6-simulated (b) mean monthly precipitation (mm), (c) mean monthly temperature $\left({ }^{\circ} \mathrm{C}\right)$ during the historical period (1980-2014)

\subsubsection{Model Simulations}

In this study, we have used 13 bias-corrected CMIP6 models for Nepal with a spatial resolution of $0.25^{\circ} \times 0.25^{\circ}$, which has been developed by Mishra et al. (2020). For bias correction, several station measurements from the south Asian region, for example, observation from India Meteorological Department (IMD), are used for the Indian region and data from Sheffield et al. (2006) for outside India. All 13 model considers the shared socioeconomic pathways (SSPs) with three climatic scenarios, such as SSP126, SSP245, and SSP585, representing the low, intermediate, and high greenhouse gas emissions, respectively (Li et al. 2020). This bias-corrected CMIP6 model provides the historical and projected precipitation, minimum temperature, and maximum temperature for all three climatic scenarios (SSP125, SSP245, and SSP585). Initially, the selected models have a different spatial resolution; however, after bias correction, all these models provide climatic datasets at $0.25^{\circ}$ spatial resolution for six south Asian countries (Bangladesh, Bhutan, India, Nepal, Pakistan, and Sri Lanka). The climatic simulations of precipitation and temperature of CMIP6 historical (1980-2014) and projected (2020-2100) were downloaded from https://zenodo.org/record/3873998\#.YKOjiqgzY2w. The selected 13 CMIP6 models' description is provided in Table 1. More details of the datasets can be accessed from
Table 1 CMIP6 models used in this study

\begin{tabular}{llcll}
\hline S. no & Model name & $\begin{array}{l}\text { Native spatial } \\
\text { resolution (degree) }\end{array}$ & $\begin{array}{l}\text { Spatial resolution after } \\
\text { bias correction (degree) }\end{array}$ & Historical (projection) \\
\hline 1 & ACCESS-CM2 & $1.25 \times 1.875$ & $0.25 \times 0.25$ & $1980-2014(2020-2100)$ \\
2 & ACCESS-ESM1-5 & $1.25 \times 1.875$ & $0.25 \times 0.25$ & $1980-2014(2020-2100)$ \\
3 & BCC-CSM2-MR & $1.121 \times 1.125$ & $0.25 \times 0.25$ & $1980-2014(2020-2100)$ \\
4 & CanESM5 & $2.790 \times 2.812$ & $0.25 \times 0.25$ & $1980-2014(2020-2100)$ \\
5 & EC-Earth3 & $0.701 \times 0.703$ & $0.25 \times 0.25$ & $1980-2014(2020-2100)$ \\
6 & EC-Earth3-Veg & $0.701 \times 0.703$ & $0.25 \times 0.25$ & $1980-2014(2020-2100)$ \\
7 & INM-CM4-8 & $1.5 \times 2$ & $0.25 \times 0.25$ & $1980-2014(2020-2100)$ \\
8 & INM-CM5-0 & $1.5 \times 2$ & $0.25 \times 0.25$ & $1980-2014(2020-2100)$ \\
9 & MPI-ESM1-2-HR & $0.935 \times 0.937$ & $0.25 \times 0.25$ & $1980-2014(2020-2100)$ \\
10 & MPI-ESM1-2-LR & $1.865 \times 1.875$ & $0.25 \times 0.25$ & $1980-2014(2020-2100)$ \\
11 & MRI-ESM2-0 & $1.1215 \times 1.125$ & $0.25 \times 0.25$ & $1980-2014(2020-2100)$ \\
12 & NorESM2-LM & $1.894 \times 2.5$ & $0.25 \times 0.25$ & $1980-2014(2020-2100)$ \\
13 & NorESM2-MM & $0.942 \times 1.25$ & $0.25 \times 0.25$ & $1980-2014(2020-2100)$ \\
\hline
\end{tabular}


Mishra et al. (2020); https://arxiv.org/abs/2006.12976. In this study, 13 CMIP6 model ensemble mean datasets (precipitation and temperature) were used to calculate the drought index (Table 2).

\subsection{Methodology}

\subsubsection{Calculation of SPEI}

We use SPEI to calculate drought in our study that uses precipitation $(\mathrm{Pi})$ and potential evapotranspiration (PETi) to calculate water balance (Di) (Eq. 1). The precise method for calculation of SPEI is described in Vicente-Serrano et al. (2010). We used a Thornthwaite method for PET calculation, which only requires monthly mean temperature (Thornthwaite, 1948). Further, Portela et al. 2019 have also suggested the Thornthwaite method over the Penman-Monteith method (complex method) for PET calculation:

$D i=P i-P E T i, i=1,2,3, \ldots \ldots . . n$

The log-logistic distribution function to fit the Di and then SPEI were obtained at 1-12 (SPEI1-SPEI12) timescales. In this study, 12-month SPEI (SPEI12) was selected to calculate drought characteristics, representing the longterm meteorological drought. SPEI12 is calculated using the temperature and precipitation of the current month and the past 11 months. The SPEI value increases with the timescales, suggesting the longer timescale is suitable for drought representation than the shorter timescale (VicenteSerrano et al. 2010; Zhai et al. 2020). The SPEI has positive $(\mathrm{SPEI} \geq 1)$ and negative $(\mathrm{SPEI} \leq-1)$ values representing wetness and dryness conditions, respectively. Therefore, -1 is the threshold for determination of drought and has three drought categories: moderate $(-1.5<\mathrm{SPEI} \leq-1)$, severe $(-2<\mathrm{SPEI} \leq-1.5)$, and extreme $(\mathrm{SPEI} \leq-2)$.

\subsubsection{Drought Characterization}

The drought events are defined as the negative SPEI $(\mathrm{SPEI} \leq-1)$ for at least two consecutive months. The drought duration (DD) is the total number of months counted between the drought initiation and drought termination time (Mishra and Singh 2010). Drought severity (DS) is the sum

Table 2 Mean drought duration, severity, intensity, and frequency during 1980-2014 for observation and CMIP6 historical

\begin{tabular}{lllll}
\hline Period & $\begin{array}{l}\text { Duration } \\
\text { (month) }\end{array}$ & Severity & Intensity & Frequency (\%) \\
\hline Observation & 7.44 & -9.73 & -1.31 & 18.57 \\
CMIP6 historical & 4.93 & -6.80 & -1.37 & 21.42 \\
\hline
\end{tabular}

of SPEI values during drought events (Eq. 2). Drought intensity (DI) is calculated as drought severity (DS) per drought duration (DD) (Eq. 3). The drought frequency (DF) is the number of drought months $(n)$ to the total number of months of years for the study period $(\mathrm{N})$, which is expressed in percentage (Eq. 4):

$\mathrm{DS}=\left(\sum_{\mathrm{i}=1}^{\mathrm{n}} \mathrm{SPEI}\right)_{\mathrm{e}}$

$D I=\frac{D S}{D D}$

$D F=\frac{n}{N} \times 100 \%$

\section{Results}

\subsection{Observed and Historical Drought Condition}

The seasonal cycle of the observed and CMIP6-simulated mean precipitation and temperature over Nepal during the historical period is shown in Fig. 1b, c. In both observation and CMIP6 historical, the maximum precipitation amount is recorded in the summer season with a peak in July and August (Fig. 1b). The correlation coefficient between observation and CMIP6 historical for precipitation is 0.95 $(p<0.01)$. However, the CMIP6 models underestimated the observed precipitation amount in the summer season and overestimated it in the winter season. In Fig. 1c, the CMIP6 slightly underestimated the monthly variation of the observed mean temperature, with a correlation coefficient of $0.99(p<0.01)$. The results indicated that the CMIP6 datasets can capture the monthly mean precipitation and temperature climatology over Nepal.

The temporal variation of SPEI12 over Nepal at all the months (January-December) for observation and CMIP6 historical during 1980-2014 is shown in Fig. 2. The drought events were mainly observed during 1990-1993, which later increased from 2005 over Nepal (Fig. 2a). Remarkably, the annual drought events are observed in 1992, 1994, 2005, 2006, 2009, and 2012. Compared to observation, CMIP6 historical datasets showed the pronounced drought events during 1980-1987, 1990-1993, and getting drier after 2005 (Fig. 2b). Both observation and CMIP6 historical showed the wetness during 1998-2004, dryness during 1990-1993, and increasing dryness after 2005 in Nepal. The SPEI monthly correlation between observation and CMIP6 historical is 0.23 , which is significant at a $99 \%$ confidence interval, indicating that the CMIP6 model can simulate the drought condition over Nepal (Fig. 2c). 


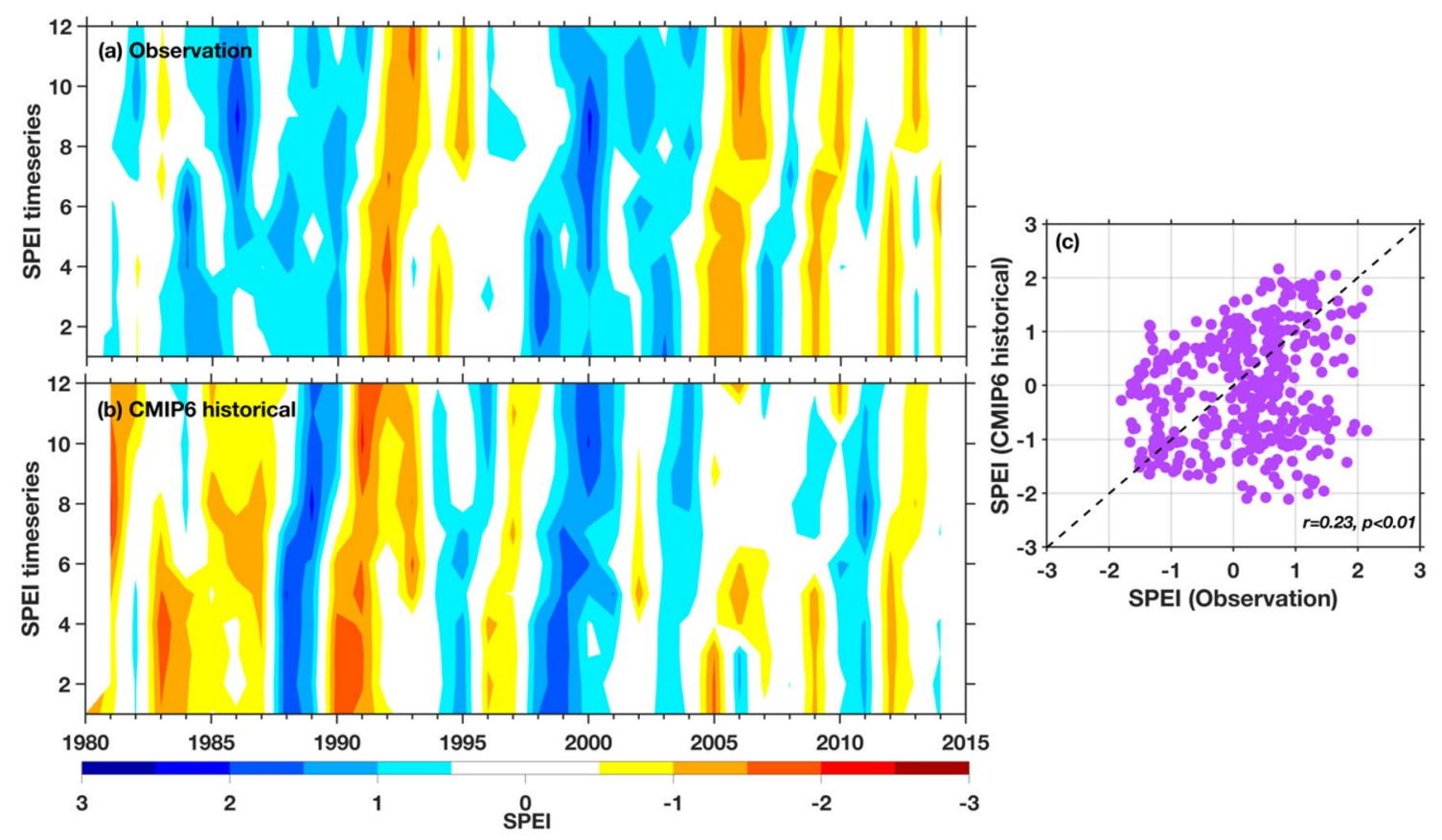

Fig. 2 Temporal variation of the monthly SPEI12 calculated from (a) observation, (b) CMIP6 historical datasets, (c) scatterplot SPEI calculated from observation, and CMIP6 historical during 1980-2014

The observed average drought duration, severity, and intensity were 7.44 months, -9.73 , and -1.31 , respectively, with frequency reaching $18.57 \%$ during 1980-2014 (Table 2). Compared to the observation, CMIP6 historical datasets slightly underestimated the duration and severity by 2.51 months and -2.93 , respectively. As of observation, CMIP6 historical datasets overestimated the intensity and frequency of drought occurrences. Such a higher frequency may be due to the extreme drought frequency in CMIP6 historical datasets, which was $3.47 \%$ higher than observation (Table 2). Moreover, the severe and moderate drought frequency was almost similar to observation. Overall, the result indicates that the CMIP6 model in Nepal can represent the drought characteristics as an observation.

\subsection{Projected Drought Condition}

The temporal variation of the SPEI12 for the projected period (2020-2100), under SSP126, SSP245, and SSP585, is shown in Fig. 3. It is projected that drought might occur in all time-series (1-12 months) and categories of the drought events, i.e., moderate, severe, and extreme. Moreover, in all scenarios, the drought events are projected to increase up to 2060 and decrease afterward (Fig. 3a-c). A recent study by Almazroui et al. (2020) projected an increase in the south Asian summer monsoon in the twenty-first century under different SSP scenarios. The decreasing drought events after 2060 may be associated with a projected increase in the south Asian summer monsoon over this region.

The average drought duration, severity, and intensity will be 5.78 months, -8.68 , and -1.50 (Fig. $4 \mathrm{a}$ ), respectively, with a frequency of $16.60 \%$ during the projected period (2020-2100) at SSP126 (Fig. 4b). Compared to CMIP6 historical, the duration and frequency will be decreased, whereas severity and intensity will be slightly increased in the projected period at SSP126. The duration and frequency show a decrement of 0.4 months and $6.2 \%$; however, the severity and intensity will be increased by -0.78 and -0.25 , respectively. Under SSP245 (SSP585) scenarios, severity and intensity will be 7.4 (10.8) months, -11.0 $(-15.98),-1.47(-1.48)$, respectively (Fig. 4a). The result further indicates that the drought characteristics will be increased in medium (SSP245) and high (SSP585) emission scenarios compared to CMIP6 historical (Figs. 3, 4). However, the drought frequency will be decreased for a projected period by $\sim 5$ to $6 \%$ at SSP245 and SSP585 than the CMIP6 historical period, which may be due to different calculation periods. The frequency of drought occurrences under SSP245 (17.5\%) is slightly higher than SSP126 (16.6\%) and SSP585 (16.8\%) scenarios (Fig. 4b). This result indicates that in the future period (2020-2100), under SSP126, SSP245, and SSP585 scenarios, mean drought duration and severity are projected to increase over Nepal, especially under SSP585. The difference in intensity was very minimal; 

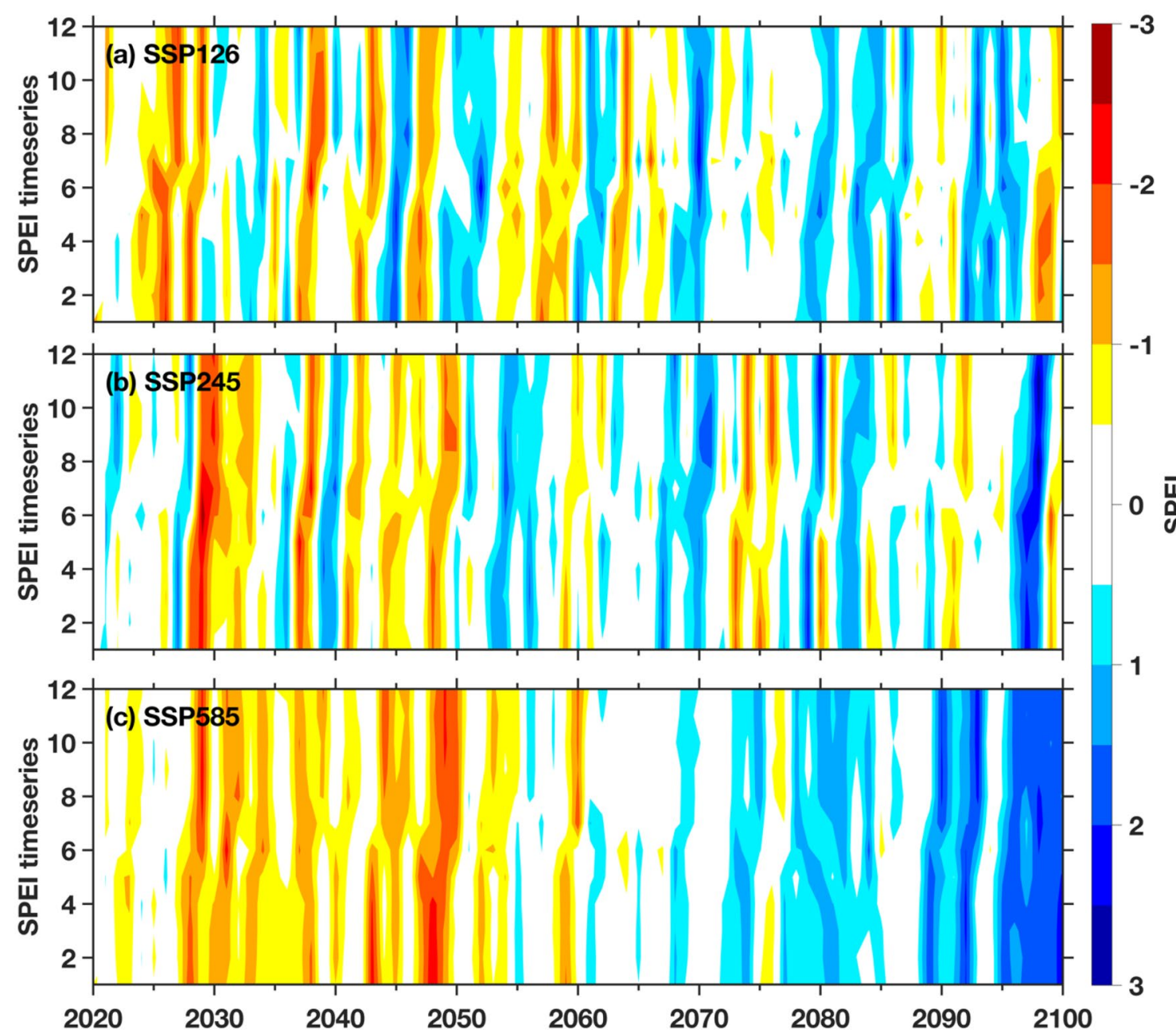

Fig. 3 Temporal variation of the monthly SPEI12 for projected period (2020-2100) calculated for CMIP6 scenarios: (a) SSP126, (b) SSP245, and (c) SSP585

however, a slightly higher intensity was observed at SSP126 than SSP245 and SSP585.

\subsection{Drought Conditions in Early and Later Future Period}

As observed in the above results, the mean drought duration, severity, and intensity over Nepal will be increased than that of the historical period (after 2014), but the frequency will be decreased, which may be due to a more extended period taken for calculation (Eq. 4). Further, occurrences of drought events are higher in the early future (2020-2060 as "P1", hereafter) than in the later future (2061-2100 as "P2" hereafter) (Fig. 3). Therefore, to study the drought characteristics, we divided the projected period into two different periods (P1 and P2) (Fig. 5). During the $\mathrm{P} 1$ period, the duration, severity, intensity, and frequency are projected to be higher (i.e., 1.4 months, -2.95 and -0.12 and $16.6 \%$, respectively) than the P2 period, at the SSP126 scenario (Figs. 5a and 6a). The result indicates that the $\mathrm{P} 2$ period will likely have a minor drought frequency with a shorter duration, less severity, and less intensive over the study region.

Compared to P1, the drought will be 2.5 months shorter and less severe by -3.5 ; however, the drought will be slightly intensive in $\mathrm{P} 2$, but the differences are minimal at SSP245 (Fig. 5b). Similarly, in P2 period will have 11.2\% less drought frequency over Nepal under SSP245 scenarios (Fig. 6b). Moreover, the extreme drought will be increased by $0.2 \%$ in the P2 period for SSP245. In the SSP585 scenario, the drought months, severity, and intensity will be 10.8 months, -15.98 , and -1.48 , respectively, at the P1 period (Fig. 5c). However, no drought occurrences will be found in the P2 period. In the SSP585 scenario, the total drought frequency occurrences will be $33.3 \%$ in the P1 period, including extreme, severe, and moderate drought frequency of $3.7 \%, 8.98$, and $20.62 \%$, respectively (Fig. 6c). The result shows the dryness is most likely to be more 

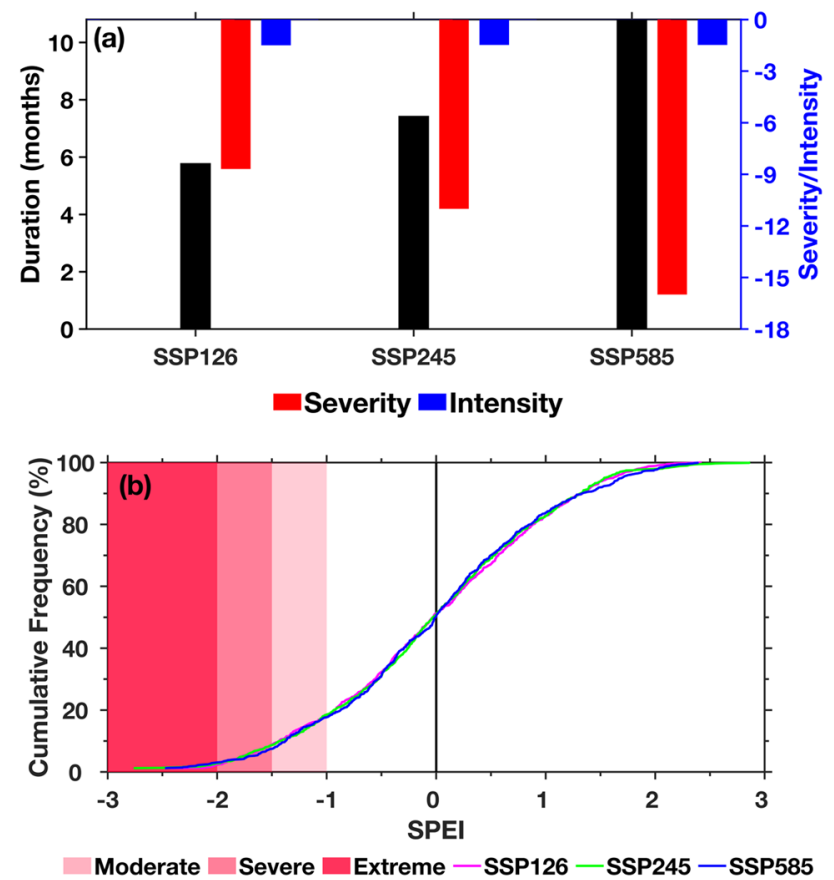

Fig. 4 a Mean drought duration (months), severity and intensity, (b) frequency of different CMIP6 scenarios (SSP126, SSP245, and SSP585) between 2020 and 2100

prolonged and severe in the P1 period under SSP585 than SSP126 and SSP245.

\section{Discussion}

This study analyzed the future evolution of droughts over Nepal in the twenty-first century under three SSP scenarios: SSP126, SSP245, and SSP585. The drought characteristics are examined by analyzing the SPEI drought index. The SPEI was computed using the observed data from 112 climatic stations in Nepal and an ensemble of 13 CMIP6 bias-corrected models. SPEI readily enabled the inclusion of the combined effect of temperature and precipitation as the essential parameters in calculating drought. The correlation between observation and CMIP6 historical datasets shows the CMIP6 models can simulate the climatology and drought characteristics over Nepal. It is also already observed that CMIP6 has improved temperature and precipitation estimation over south Asia (Almazroui et al. 2020), leading to satisfactory performances in capturing the drought characteristics over south Asia (Aadhar and Mishra 2020; Zhai et al. 2020).

In the observational period, it has been noticed that droughts have mainly increased after 2005 over Nepal. This is in agreement with the recent studies conducted over Nepal (Hamal et al. 2020b; Hamal et al. 2021; Sharma et al. 2021).
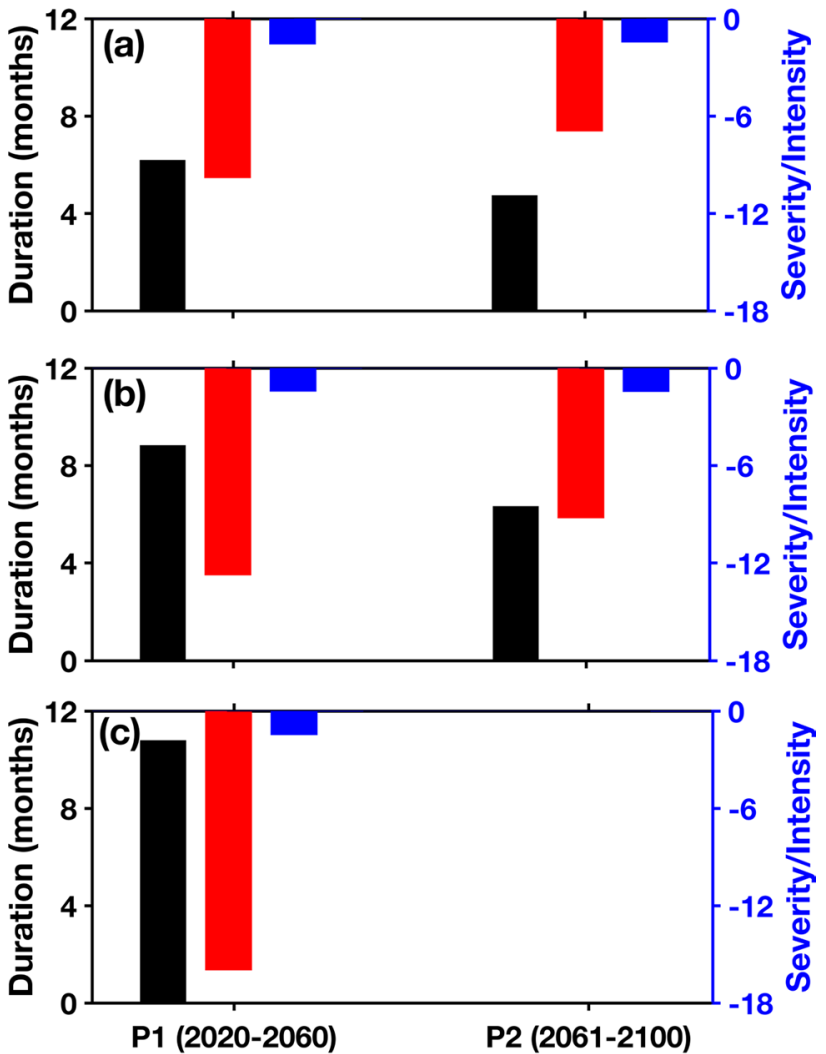

Duration $\square$ Severity $\square$ Intensity

Fig. 5 The drought duration, severity, and intensity for (a) SSP126, (b) SSP245, and (c) SSP585 during 2020-2060 (P1) and 2061-2100 (P2)

The present study further examined the projected drought characteristics from 2020 to 2100 . Our results indicate that all types of drought categories (i.e., moderate, severe, and extreme) are likely to occur in the projected period. The duration, severity, and intensity increase with the increasing greenhouse gas emission in the future period. The mean drought duration and severity are longer and severe under the high emission scenario SSP585, which is reported by ( $\mathrm{Li}$ et al. 2020). The frequency of drought occurrences under SSP245 (17.5\%) is slightly higher than SSP126 (16.6\%) and SSP585 (16.8\%) scenarios. Moreover, the drought frequency will decrease simultaneously from low to high emission scenarios (Zhai et al. 2020).

The result further shows that drought occurrences are likely to be frequent with a longer duration and higher severity from early (2020-2060) to the later future (2061-2100). These changes in the drought conditions over the study region could be related to the changes in precipitation and temperature (Almazroui et al. 2020; Chen and Sun 2015; Yang et al. 2013). The precipitation is relatively lower in the P1 period than in the P2 period (Fig. 7a). The precipitation deficit coupled with temperature-induced evapotranspiration 


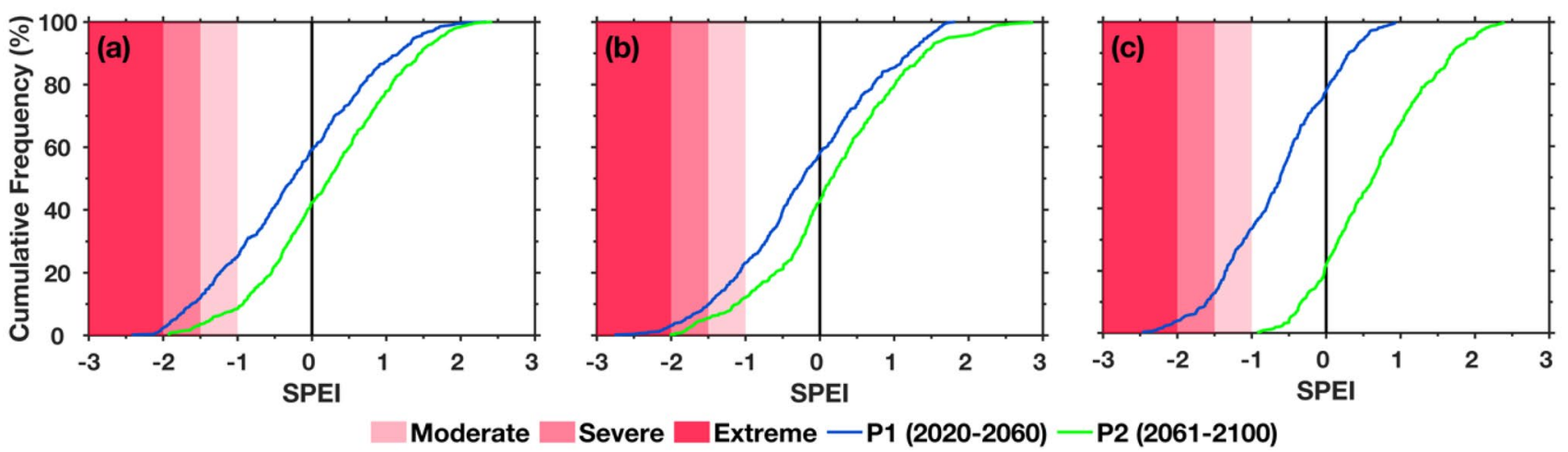

Fig. 6 Drought frequency curves under three different SSP scenarios: (a) SSP126, (b) SSP245, and (c) SSP585. The blue (green) curve indicates drought frequency for the period 2020-2060 (2061-2100)

may lead to the occurrence of drought events at different scenarios in the early future (Dai et al. 2018). Moreover, the precipitation starts to increase after the 2060s; therefore, there are fewer drought conditions though a sharp increase in temperature was also observed. A similar drought condition was projected for the north, east, and north-central regions of south Asia due to increased precipitation at annual and seasonal timescales (Zhai et al. 2020). The increment in the future evapotranspiration with an increase in temperature may lead to fewer drought events in the later future period (Fig. 7b, c). The CMIP6 model projected the extreme drought during 2048 (SPEI $=-2.47$ ), where the precipitation anomaly is $-1.29 \mathrm{~mm}$ with the temperature and evapotranspiration anomaly of $-0.58{ }^{\circ} \mathrm{C}$ and $-0.59 \mathrm{~mm}$ under the high emission (SSP585) scenario, respectively. Similarly, under the same scenario, the year 2100 is projected extremely wet (SPEI $=2.38$ ), precipitation, temperature, and evapotranspiration anomaly of $2.68 \mathrm{~mm}, 1.79^{\circ} \mathrm{C}$, and $1.82 \mathrm{~mm}$, respectively (Fig. 7). Moreover, these results suggest that the change in precipitation may have a significant role in determining the future drought conditions than the temperature and evaporation over the southern slope of Central Himalaya, Nepal.

The projected drought characteristics in the present study are only considered in annual timescale (SPEI12); however, these drought characteristics may vary in the seasonal timescale. Therefore, further studies can include a seasonal timescale to get detailed information for the projected seasonal drought conditions over the country.

\section{Conclusions}

We analyzed data from 112 climatic stations and an ensemble mean of 13 bias-corrected CMIP6 models (historical and projected datasets) to examine the drought conditions over Nepal in the twenty-first century. The widely used SPEI has been applied to study droughts and their variability at SPEI12 timescales. The observation and CMIP6 historical datasets show wetness during 1998-2004, dryness during 1990-1993, and increasing dryness after 2005. During the historical period (1980-2014), CMIP6 datasets depict the drought conditions over Nepal that resemble the observations. We further examine the future projections of droughts over Nepal. The projected period is covering all categories (moderate, severe, and extreme) of drought events. Our study suggests an increase in the duration and severity of droughts over Nepal with increasing greenhouse gas emissions (i.e., SSP585). The drought intensity is projected to increase under the SSP126 scenario, whereas under SSP245, the drought frequency will be slightly higher. Our results further indicate enhanced frequency, duration, and severity of droughts over Nepal in the near future (2020-2060) compared to the end century period (2061-2100). In the context of the ongoing climate change, this study could thus be helpful for the preparation and implementation of preparedness and adaptation strategies to counter the imminent climate-related threats such as drought and drought-related loss. 
Fig. 7 Annual projected anomaly: (a) precipitation, (b) mean temperature, and (c) PET of different CMIP6 scenarios (SSP126, SSP245, and SSP585) during 2020-2100
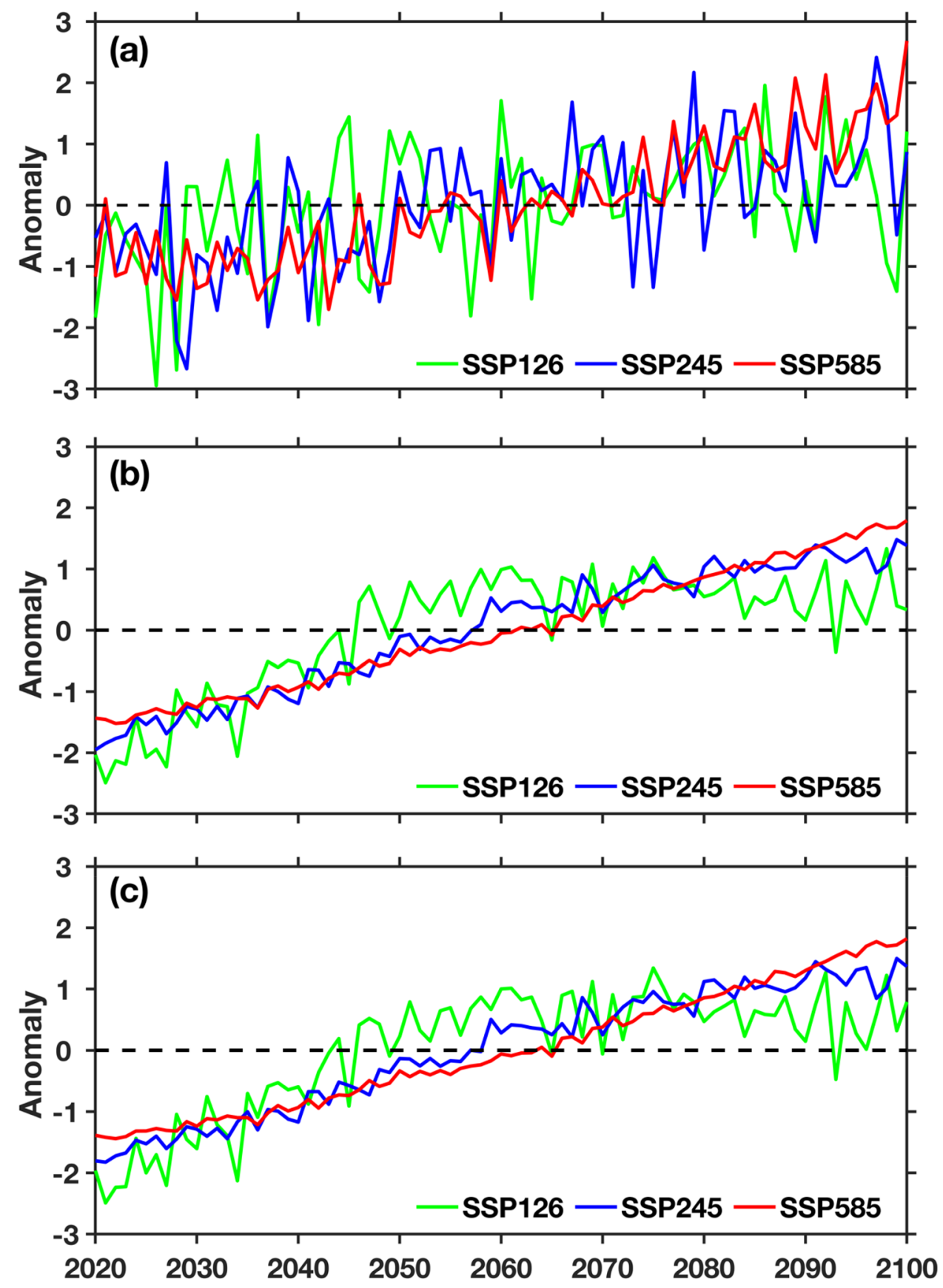

Acknowledgements We acknowledge the DHM for providing precipitation and temperature data. Mishra et al. (2020) are also greatly acknowledged for providing bias-corrected CMIP6 data for Nepal. We would also like to thank the editor and three anonymous reviewers for their insightful comments and suggestions, which helped to improve the manuscript.

Author Contributions Conceptualization: SS; methodology: SS and $\mathrm{KH}$; formal analysis and investigation: $\mathrm{SS}$ and $\mathrm{KH}$; writing-original draft preparation: SS; writing — review, and editing: KH, SS, MA, NK, MS, GH, BD, MAE and SS; supervision: BD.
Funding This research did not receive any internal and external funding. This research is conducted independently by the authors as a part of their research and study. The organization and institution mentioned in the study have no role in the design and funding of the study.

Data availability The bias-corrected CMIP6 data for Nepal can be freely obtained from https://zenodo.org/record/3873998\#.YIujN GYzYTs. Observed precipitation and temperature data can be purchased from Department of Hydrology and Meteorology, Government of Nepal (www.dhm.gov.np). 


\section{Declarations}

Conflict of interest The authors declare that they have no conflict of interest.

Open Access This article is licensed under a Creative Commons Attribution 4.0 International License, which permits use, sharing, adaptation, distribution and reproduction in any medium or format, as long as you give appropriate credit to the original author(s) and the source, provide a link to the Creative Commons licence, and indicate if changes were made. The images or other third party material in this article are included in the article's Creative Commons licence, unless indicated otherwise in a credit line to the material. If material is not included in the article's Creative Commons licence and your intended use is not permitted by statutory regulation or exceeds the permitted use, you will need to obtain permission directly from the copyright holder. To view a copy of this licence, visit http://creativecommons.org/licenses/by/4.0/.

\section{References}

Aadhar S, Mishra V (2020) On the occurrence of the worst drought in South Asia in the observed and future climate. Environ Res Lett 16(2):024050

Ali M, Asad F, Zhu H, Ahmed M, Sigdel SRH, Ru SSL, Eryun HI, Yaseen T (2019) Dendrochronological Investigation of selected Conifers from Karakoram-Himalaya. Northern Pakistan Pak J Bot 53:3

Almazroui M, Saeed S, Saeed F, Islam MN, Ismail M (2020) Projections of precipitation and temperature over the South Asian countries in CMIP6. Earth Syst Environ 4:297-320

Almazroui M, Ashfaq M, Islam MN, Rashid IU, Kamil S, Abid MA, O'Brien E, Ismail M, Reboita MS, Sörensson AA (2021a) Assessment of CMIP6 performance and projected temperature and precipitation changes over South America. Earth Syst Environ 1:1-29

Almazroui M, Islam MN, Saeed F, Saeed S, Ismail M, Ehsan MA, Diallo I, O’Brien E, Ashfaq M, Martínez-Castro D (2021b) Projected changes in temperature and precipitation over the United States, Central America, and the Caribbean in CMIP6 GCMs. Earth Syst Environ 5:1-24

Bazaz A, Bertoldi P, Buckeridge M, Cartwright A, de Coninck H, Engelbrecht F, Jacob D, Hourcade J-C, Klaus I, de Kleijne K (2018) Summary for urban policymakers: what the IPCC Special Report on global warming of $1.5^{\circ} \mathrm{C}$ means for cities.

Chandrasekara SS, Kwon H-H, Vithanage M, Obeysekera J, Kim T-W (2021) Drought in South Asia: A review of drought assessment and prediction in South Asian countries. Atmosphere 12:369

Chen H, Sun J (2015) Changes in drought characteristics over China using the standardized precipitation evapotranspiration index. $\mathrm{J}$ Clim 28:5430-5447

Cook E, D'Arrigo R, Cole J, Stahle D, Villalba R (2000) Tree-ring records of past ENSO variability and forcing. El Niño and the Southern Oscillation: multiscale variability and global and regional impacts 297-323.

Core Team R (2013) R: A language and environment for statistical computing. Vienna, Austria: R Foundation for Statistical Computing. Available.

Dahal P, Shrestha NS, Shrestha ML, Krakauer NY, Panthi J, Pradhanang SM, Jha A, Lakhankar T (2016) Drought risk assessment in central Nepal: temporal and spatial analysis. Nat Hazards 80:1913-1932

Dai A, Zhao T, Chen J (2018) Climate change and drought: a precipitation and evaporation perspective. Curr Climate Change Rep 4:301-312
De Silva M, Kawasaki A (2018) Socioeconomic vulnerability to disaster risk: a case study of flood and drought impact in a rural Sri Lankan community. Ecol Econ 152:131-140

Dogan S, Berktay A, Singh VP (2012) Comparison of multi-monthly rainfall-based drought severity indices, with application to semiarid Konya closed basin, Turkey. J Hydrol 470:255-268

Dosio A, Jury MW, Almazroui M, Ashfaq M, Diallo I, Engelbrecht FA, Klutse NA, Lennard C, Pinto I, Sylla MB (2021) Projected future daily characteristics of African precipitation based on global (CMIP5, CMIP6) and regional (CORDEX, CORDEX-CORE) climate models. Climate Dynamics pp. 1-24.

Duncan JMA, Biggs EM, Dash J, Atkinson PM (2013) Spatio-temporal trends in precipitation and their implications for water resources management in climate-sensitive Nepal. Appl Geogr 43:138-146. https://doi.org/10.1016/j.apgeog.2013.06.011

Ehsan MA (2020) Potential predictability and skill assessment of boreal summer surface air temperature of South Asia in the North American multimodel ensemble. Atmos Res 241:104974

Ehsan MA, Tippett MK, Almazroui M, Ismail M, Yousef A, Kucharski F, Omar M, Hussein M, Alkhalaf AA (2017) Skill and predictability in multimodel ensemble forecasts for Northern Hemisphere regions with dominant winter precipitation. Clim Dyn 48:3309-3324

Ehsan MA, Kucharski F, Almazroui M (2020) Potential predictability of boreal winter precipitation over central-southwest Asia in the North American multi-model ensemble. Clim Dyn 54:473-490

Ehsan MA, Tippett MK, Robertson AW, Almazroui M, Ismail M, Dinku T, Acharya N, Siebert A, Ahmed JS, Teshome A (2021) Seasonal predictability of Ethiopian Kiremt rainfall and forecast skill of ECMWF's SEAS5 model. Climate Dyn 24:1-17

Hamal K, Sharma S, Baniya B, Khadka N, Zhou X (2020a) Interannual variability of winter precipitation over Nepal coupled with ocean-atmospheric patterns during 1987-2015. Front Earth Sci 8:161. https://doi.org/10.3389/feart.2020.00161

Hamal K, Sharma S, Khadka N, Haile GG, Joshi BB, Xu T, Dawadi B (2020b) Assessment of drought impacts on crop yields across Nepal during 1987-2017. Meteorol Appl 27:e1950

Hamal K, Sharma S, Pokharel B, Shrestha D, Talchabhadel R, Shrestha A, Khadka N (2021) Changing pattern of drought in Nepal and associated atmospheric circulation. Atmos Res 4:105798

Huo-Po C, Jian-Qi S, Xiao-Li C (2013) Future changes of drought and flood events in China under a global warming scenario. Atmos Oceanic Sci Lett 6:8-13

Kansakar SR, Hannah DM, Gerrard J, Rees G (2004) Spatial pattern in the precipitation regime of Nepal. Int J Climatol 24:1645-1659. https://doi.org/10.1002/joc.1098

Karki R, Talchabhadel R, Aalto J, Baidya SK (2015) New climatic classification of Nepal. Theoret Appl Climatol 125:799-808. https:// doi.org/10.1007/s00704-015-1549-0

Kidd C, Huffman G (2011) Global precipitation measurement. Meteorol Appl 18:334-353

Kim J-B, So J-M, Bae D-H (2020) Global warming impacts on severe drought characteristics in Asia monsoon region. Water 12:1360

Li S-Y, Miao L-J, Jiang Z-H, Wang G-J, Gnyawali KR, Zhang J, Zhang H, Fang K, He Y, Li C (2020) Projected drought conditions in Northwest China with CMIP6 models under combined SSPs and RCPs for 2015-2099. Adv Clim Chang Res 11:210-217

Van Loon AF, Stahl K, Di Baldassarre G, Clark J, Rangecroft S, Wanders N, Gleeson T, Van Dijk AI, Tallaksen LM, Hannaford J (2016) Drought in a human-modified world: reframing drought definitions, understanding, and analysis approaches.

McKee TB, Doesken NJ, Kleist J (1993) The relationship of drought frequency and duration to time scales. Proceedings of the 8th Conference on Applied Climatology. Boston. pp 179-183

Mishra AK, Singh VP (2010) A review of drought concepts. J Hydrol 391:202-216 
Mishra V, Bhatia U, Tiwari AD (2020) Bias-corrected climate projections for South Asia from coupled model intercomparison project-6. Scient Data 7:1-13

Nayava JL (1980) Rainfall in Nepal. Himal Rev 12:1-18

Nepal B, Shrestha D, Sharma S, Shrestha MS, Aryal D, Shrestha N (2021) Assessment of GPM-Era Satellite Products' (IMERG and GSMaP) ability to detect precipitation extremes over mountainous country Nepal. Atmosphere 12:254

Portela MM, Santos J, de Carvalho Studart TM (2019) Effect of the evapotranspiration of thornthwaite and of penman-monteith in the estimation of monthly streamflows based on a monthly water balance Model. Current Practice in Fluvial GeomorphologyDynamics and Diversity. IntechOpen

Riahi K, Van Vuuren DP, Kriegler E, Edmonds J, Oneill BC, Fujimori S, Bauer N, Calvin K, Dellink R, Fricko O (2017) The shared socioeconomic pathways and their energy, land use, and greenhouse gas emissions implications: an overview. Global Environ Change 42:153-168

Sharma S, Chen Y, Zhou X, Yang K, Li X, Niu X, Hu X, Khadka N (2020a) Evaluation of GPM-Era satellite precipitation products on the Southern Slopes of the central himalayas against rain gauge data. Remote Sens 12:1836. https://doi.org/10.3390/rs12111836

Sharma S, Hamal K, Khadka N, Joshi BB (2020b) Dominant pattern of year-to-year variability of summer precipitation in Nepal during 1987-2015. Theoret Appl Climatol 142:1071-1084. https://doi. org/10.1007/s00704-020-03359-1

Sharma S, Khadka N, Hamal K, Baniya B, Luintel N, Joshi BB (2020c) Spatial and temporal analysis of precipitation and its extremities in seven provinces of Nepal (2001-2016). Appl Ecol Environ Sci 8:64-73. https://doi.org/10.12691/aees-8-2-4

Sharma S, Hamal K, Khadka N, Shrestha D, Aryal D, Thakuri S (2021) Drought characteristics over Nepal Himalaya and their relationship with climatic indices. Meteorol Appl 28:e1988

Sheffield J, Goteti G, Wood EF (2006) Development of a 50-year highresolution global dataset of meteorological forcings for land surface modeling. J Clim 19:3088-3111
Sheffield J, Wood EF, Roderick ML (2012) Little change in global drought over the past 60 years. Nature 491:435-438. https://doi. org/10.1038/nature 11575

Shrestha D, Sharma S, Hamal K, Jadoon UK, Dawadi B (2021) Spatial distribution of extreme precipitation events and its trend in Nepal. Environ Sci 9:58-66

Thornthwaite CW (1948) An approach toward a rational classification of climate. Geogr Rev 38:55-94

Van Dijk AI, Beck HE, Crosbie RS, de Jeu RA, Liu YY, Podger GM, Timbal B, Viney NR (2013) The Millennium Drought in southeast Australia (2001-2009): natural and human causes and implications for water resources, ecosystems, economy, and society. Water Resour Res 49:1040-1057

Vicente-Serrano SM, Beguería S, López-Moreno JI (2010) A multiscalar drought index sensitive to global warming: the standardized precipitation evapotranspiration index. J Clim 23:1696-1718. https://doi.org/10.1175/2009jcli2909.1

Wang S-Y, Yoon J-H, Gillies RR, Cho C (2013) What caused the winter drought in western Nepal during recent years?*,+. J Clim 26:8241-8256. https://doi.org/10.1175/jcli-d-12-00800.1

Xu Y, Zhang X, Wang X, Hao Z, Singh VP, Hao F (2019) Propagation from meteorological drought to hydrological drought under the impact of human activities: a case study in northern China. $\mathrm{J}$ Hydrol 579:124147

Yang P, Xiao Z, Yang J, Liu H (2013) Characteristics of clustering extreme drought events in China during 1961-2010. Acta Meteor Sin 27:186-198

Zhai J, Mondal SK, Fischer T, Wang Y, Su B, Huang J, Tao H, Wang G, Ullah W, Uddin MJ (2020) Future drought characteristics through a multi-model ensemble from CMIP6 over South Asia. Atmos Res 246:105111

Zhou W, Gang C, Zhou F, Li J, Dong X, Zhao C (2015) Quantitative assessment of the individual contribution of climate and human factors to desertification in northwest China using net primary productivity as an indicator. Ecol Ind 48:560-569 